\title{
Inkwelling increases benign stricture formation after Ivor Lewis esophagogastrectomy
}

\author{
Enoch Akowuah, MD, MRCS, Manfred Junemann-Ramirez, FRCS, Odunayo Kalejayie, MBCHB, and \\ Joseph Rahamim, FRCS, Plymouth, Devon, United Kingdom
}

I nkwelling (reinforcement of the gastroesophageal anastomosis) may reduce anastomotic leak rates after Ivor Lewis esophagogastrectomy. The technique was first described by Procter $^{1}$ in 1967 and is routinely used by surgeons.

However, as our understanding of the causes of anastomotic dehiscence has improved, for example, the role of preoperative and postoperative nutritional status, and new surgical techniques have developed, principally the use of stapling devices, the usefulness of the inkwelling procedure in reducing anastomotic leak is debatable. A possible drawback of inkwelling is that it may lead to a narrowing of the gastroesophageal anastomotic site and therefore potentially increase the incidence of benign esophageal strictures. We routinely performed inkwelling of the gastroesophageal anastomotic site in our practice. However, after a review of our data suggested that inkwelling did not affect the rate of anastomotic dehiscence, the technique was abandoned. ${ }^{2}$ In this study, we compared the rates of benign esophageal stricture in patients having Ivor Lewis gastroesophagectomy, with or without inkwelling.

\section{Methods}

A retrospective review of all patients who underwent Ivor Lewis gastroesophageal resections from 1992 to 2004 in our unit was performed. Inkwelling was performed with 3-0 double-ended Prolene polypropylene sutures (Ethicon, Inc, Somerville, NJ). The adventitia of the proximal stomach and distal esophagus were anastomosed in 4 equidistant areas with a partial-thickness horizontal mattress technique as described by Proctor. ${ }^{1}$ The stitches were placed at least $2 \mathrm{~cm}$ from the stapled anastomosis and therefore led to inkwelling of the anastomosis within the gastric tube (Figure 1).

Benign esophageal stricture was diagnosed when patients had symptoms of dysphagia necessitating upper gastrointestinal endoscopy and dilatation or stent. Before dilatation, if the clinical picture or endoscopic examination suggested a malignant recurrence, multiple biopsy specimens were taken. Patients were classified as having a benign anastomotic stricture only when malignant recurrence had been ruled out by histologic examination.

From the Department of Cardiothoracic Surgery, Derriford Hospital, Plymouth NHS Trust, Plymouth, Devon, United Kingdom.

Received for publication Aug 12, 2006; accepted for publication Sept 28, 2006.

Address for reprints: Enoch Akowuah, MD, MRCS, Department of Cardiothoracic Surgery, Derriford Hospital, Plymouth NHS Trust, Plymouth Devon, PL6 8DH, United Kingdom (E-mail: akowuah@yahoo.com).

J Thorac Cardiovasc Surg 2007;133:581-2

$0022-5223 / \$ 32.00$

Copyright $\odot 2007$ by The American Association for Thoracic Surgery doi:10.1016/j.jtcvs.2006.09.031

\section{Results}

A total of 495 patients were studied. The in-hospital mortality was $7.5 \%$ (37 deaths). Anastomotic leak rate including asymptomatic leaks diagnosed during postoperative screening and clinical anastomotic dehiscence occurred in $33(6.7 \%)$ patients.

Mean age was 66 years $(\mathrm{SD}=9.6$ years); $337(68 \%)$ of the patients were male. Tumor histologic classification was as follows: adenocarcinoma, $348(70.3 \%)$ patients; squamous cell carcinoma, $109(22 \%)$ patients; and undifferentiated $7(1.4 \%)$ patients. The remaining $6.6 \%$ of tumors were of mixed histologic type (16 patients), oat cell (3 patients), anaplastic (10 patients), large cell (1 patient), and neuroendocrine (1 patient).

The Ivor Lewis esophagogastrectomy cohort was divided into two groups. Group A, 376 (76\%) patients, had inkwelling performed and group B, 119 patients (24\%), did not. Anastomotic leak rates were similar in the two groups (23 [6.1\%] patients in group A versus 10 [8.4\%] patients in group B; $P=.4$ ).

In group A, $183(48.7 \%)$ patients had a benign stricture necessitating dilatation compared with only 39 (34.8\%) patients with a stricture in group B $(P<.001)$. Patients in group A underwent a mean of $2.5(\mathrm{SD}=1.8)$ procedures, with $1.19(\mathrm{SD}=1.3)$ procedures for patients in group $\mathrm{B}(P=.03)$.

\section{Discussion}

Benign anastomotic stricture necessitating dilation is a frequent complication after esophageal resection. The reported incidences vary from $10 \%$ to $50 \%{ }^{3}$ When it occurs early after the procedure, it delays weight gain and general recovery. When it occurs as a late complication, it significantly impairs the quality of life of the

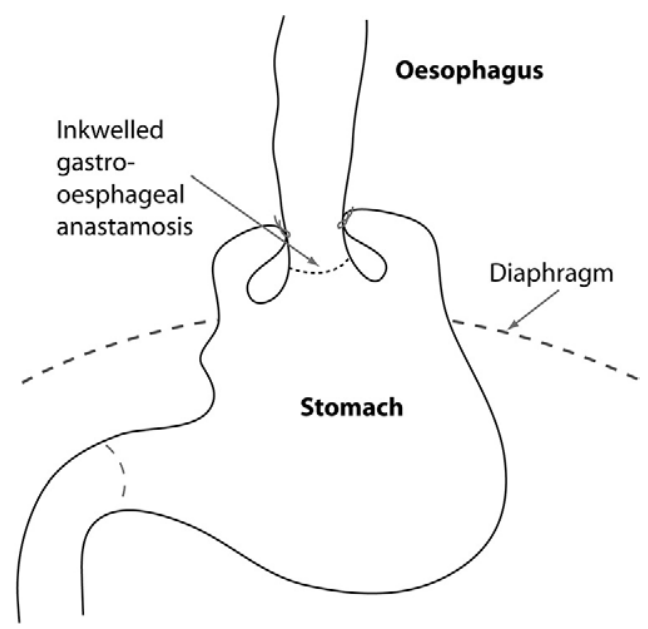

Figure 1. Line diagram of the inkwelling procedure in cross section. 
patients. In this study, we have shown that inkwelling significantly increases the incidence of benign anastomotic stricture after Ivor Lewis esophagogastrectomy without affecting that rate of anastomotic dehiscence. Of note is that our study shows a high rate of benign anastomotic stricture. A similar incidence of benign anastomotic stricture has been reported in other series. ${ }^{4}$ The incidence of stricture is influenced considerably by its definition and the quality of follow-up. In our center, patients are followed up every 6 months for life, and this may explain our high stricture detection rate.

Our study is limited by the fact that it is a retrospective nonrandomized study; therefore, we were not able to control for other factors that may have influenced stricture formation, for example, staple size. ${ }^{5}$

In conclusion, life expectancy is limited in most patients after Ivor Lewis esophagogastrectomy; 5-year survival in our unit is $22 \%,{ }^{2}$ and so for the majority of patients the benefit of the procedure is excellent palliation with rapid and long-term relief of dysphagia. The development of anastomotic stricture therefore reduces the benefit of the operation and casts doubts on the utility of palliation. Inkwelling of the gastroesophageal anastomosis increases benign anastomotic stricture formation.

\section{References}

1. Procter DS. The 'ink-well' anastomosis in oesophageal reconstruction. $S$ Afr Med J. 1967:25;41:187-90.

2. Junemann-Ramirez M, Awan MY, Khan ZM, Rahamim JS. Anastomotic leakage post-esophagogastrectomy for esophageal carcinoma: retrospective analysis of predictive factors, management and influence on longterm survival in a high volume centre. Eur J Cardiothorac Surg.2005:27;3-7.

3. Lam TC, Fok M, Cheng SW, Wong J. Anastomotic complications after esophagectomy for cancer: a comparison of neck and chest anastomoses. J Thorac Cardiovasc Surg.1992:104;395-400.

4. Honkoop P, Siersema PD, Tilanus HW, Stassen LP, Hop WC, van Blankenstein M. Benign anastomotic strictures after transhiatal esophagectomy and cervical esophagogastrostomy: risk factors and management. J Thorac Cardiovasc Surg.1996:111;1141-6.

5. Pierie JP, de Graaf PW, Poen H, van der Tweel I, Obertop H. Incidence and management of benign anastomotic stricture after cervical oesophagogastrostomy. Br J Surg.1993:80;471-4.

\section{Tuberculosis presenting as an endobronchial mass}

Daniel Kreisel, MD, PhD, ${ }^{a}$ Nimmi Arora, MD, ${ }^{\mathrm{b}}$ Scott A. Weisenberg, MD, ${ }^{c}$ Anjali Saqi, MD, ${ }^{d}$ Alexander S. Krupnick, MD, ${ }^{a}$ Anna M. Demetriades, MD, ${ }^{\mathrm{b}}$ Chris lakovou, MD, ${ }^{\mathrm{e}}$ Rick Conetta, MD, ${ }^{\mathrm{e}}$ and Paul C. Lee, MD, ${ }^{\mathrm{b}}$ St Louis, Mo, and New York, NY

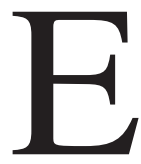
ndobronchial tuberculosis has become a rare condition in developed countries. Furthermore, tuberculosis is often not considered in the differential diagnosis of endobronchial masses. Thus diagnosis is often delayed because of the rarity of this condition and the nonspecific nature of the symptoms. This case report describes endobronchial tuberculosis in a young previously healthy woman.

\section{Clinical Summary}

A 25-year-old woman with a past history of asthma presented with new onset of a dry cough. This was associated with symptoms of

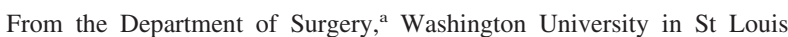
St Louis, Mo; the Departments of Cardiothoracic Surgery, ${ }^{\mathrm{b}}$ Medicine, ${ }^{\mathrm{c}}$ and Pathology, ${ }^{\mathrm{d}}$ Weill Medical College of Cornell University, New York, NY; and the Department of Medicine, ${ }^{\mathrm{e}}$ New York Hospital Queens, New York, NY

Received for publication April 25, 2006; accepted for publication Sept 28, 2006.

Address for reprints: Daniel Kreisel, MD, PhD, Department of Surgery, Washington University, Campus Box 8234, 600 S Euclid Ave, St Louis, MO 63110 (E-mail: kreiseld@wudosis.wustl.edu).

J Thorac Cardiovasc Surg 2007;133:582-4

$0022-5223 / \$ 32.00$

Copyright $\odot 2007$ by The American Association for Thoracic Surgery doi:10.1016/j.jtcvs.2006.09.040 fatigue and anorexia. The patient had emigrated from the Philippines to the United States several years ago and had been employed as an office manager in a garment store for the last 18 months. A PPD tuberculin skin test result was negative when she started that employment. A few weeks after the onset of her cough, she had right-sided pleuritic chest pain and worsening shortness of breath. A chest radiograph showed an opacity in her right lower lung field. She was thought to have pneumonia and was started on oral antibiotics. Because her symptoms failed to improve, a chest computed tomographic scan was obtained that demonstrated dense consolidation of her right middle and right lower lobes. It also showed an endobronchial lesion in her right mainstem bronchus at the level of the takeoff of her right upper lobe bronchus (Figure 1). Of note, bronchoalveolar lavage smears obtained at this initial flexible bronchoscopy were negative for acid-fast bacilli, and she was referred to the thoracic surgery service. Flexible bronchoscopy at our institution showed an endobronchial mass in her right mainstem bronchus opposite the orifice of her right upper lobe bronchus. This mass was nearly totally obstructing the airway and was covered with caseous material. The mass was cored out with a rigid bronchoscope. Histologic examination revealed necrotizing granulomatous inflammation, and rare mycobacterial organisms were demonstrated with acid-fast stain (Figure 2). A PPD tuberculin skin test result was positive, with an induration of $20 \mathrm{~mm}$ at 48 hours. Of note, she had negative test results for HIV. The patient was treated with isoniazid, rifampin (INN: rifampicin), 